\title{
Erratum to: Laurate Permeates the Paracellular Pathway for Small Molecules in the Intestinal Epithelial Cell Model HT-29/B6 via Opening the Tight Junctions by Reversible Relocation of Claudin-5
}

Isabel Dittmann • Maren Amasheh • Susanne M. Krug • Alexander G. Markov • Michael Fromm • Salah Amasheh

Published online: 23 December 2014

(C) Springer Science+Business Media New York 2014

\section{Erratum to: Pharm Res}

DOI 10.1007/s11095-014-1350-2

The published article contains a typographical error in the title. The second word in the title (Permeates) should be "Permeabilizes". The correct article title appears below. Laurate Permeabilizes the Paracellular Pathway for Small Molecules in the Intestinal Epithelial Cell Model HT-29/B6 via Opening the Tight Junctions by Reversible Relocation of Claudin-5

The online version of the original article can be found at http://dx.doi.org/l0. |007/s | |095-0|4-1350-2.

I. Dittmann · S. M. Krug • M. Fromm

Institute of Clinical Physiology, Charité, Campus Benjamin Franklin

I 2200 Berlin, Germany

\section{Amasheh}

Department of Gastroenterology

Infectiology and Rheumatology, Division of Nutritional Medicine

Charité, Campus Benjamin Franklin

12200 Berlin, Germany

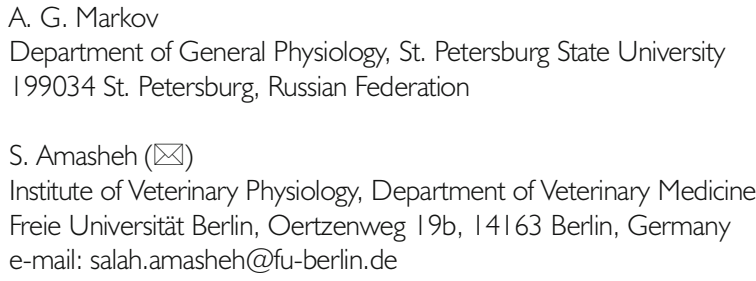

